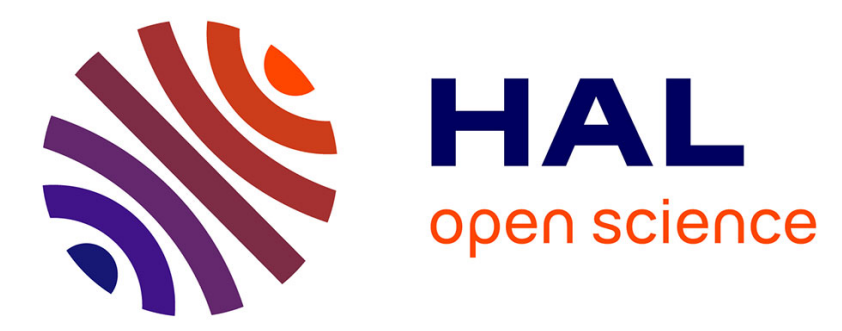

\title{
Chicks from stressed females elicit overprotective behaviour in adoptive mother quail
}

Nadège Aigueperse, Cécilia Houdelier, Océane Le Bot, Emmanuel de Margerie, Sophie Lumineau

\section{- To cite this version:}

Nadège Aigueperse, Cécilia Houdelier, Océane Le Bot, Emmanuel de Margerie, Sophie Lumineau. Chicks from stressed females elicit overprotective behaviour in adoptive mother quail. Behavioural Processes, 2020, 179, pp.104193. 10.1016/j.beproc.2020.104193 . hal-02891636

HAL Id: hal-02891636

https://hal-univ-rennes1.archives-ouvertes.fr/hal-02891636

Submitted on 20 Jul 2020

HAL is a multi-disciplinary open access archive for the deposit and dissemination of scientific research documents, whether they are published or not. The documents may come from teaching and research institutions in France or abroad, or from public or private research centers.
L'archive ouverte pluridisciplinaire HAL, est destinée au dépôt et à la diffusion de documents scientifiques de niveau recherche, publiés ou non, émanant des établissements d'enseignement et de recherche français ou étrangers, des laboratoires publics ou privés.

\section{(이) $\$$}

Distributed under a Creative Commons Attribution - NonCommercial - NoDerivatives| 4.0 
Nadège Aigueperse, Cécilia Houdelier, Océane Le Bot, Emmanuel de Margerie, Sophie Lumineau. Chicks from stressed females elicit overprotective behaviour in adoptive mother quail. Behavioural Processes, Elsevier, 2020, pp.104193. 〈10.1016/j.beproc.2020.104193〉. 〈hal02891636>

\section{Authors'pre-print}

Editor's version available at the following:

https://doi.org/10.1016/j.beproc.2020.104193

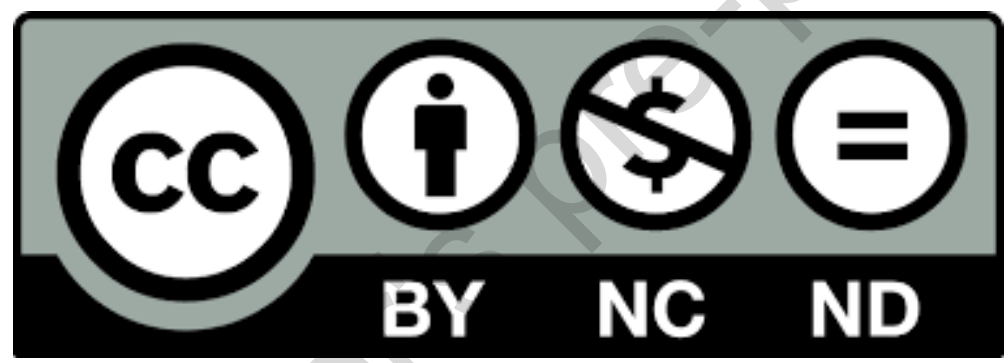




\section{CHICKS FROM STRESSED FEMALES ELICIT OVERPROTECTIVE BEHAVIOUR IN ADOPTIVE MOTHER QUAIL}

Nadège AIGUEPERSE ${ }^{\mathrm{a}, 1}$, Cécilia HOUDELIER ${ }^{\mathrm{a}}$, Océane LE BOT ${ }^{\mathrm{a}}$, Emmanuel de MARGERIE ${ }^{\mathrm{b}}$, Sophie LUMINEAU ${ }^{\mathrm{a},{ }^{*}}$

${ }^{\text {a } U n i v e r s i t e ́ ~ d e ~ R e n n e s, ~ C N R S, ~ U n i v e r s i t e ́ ~ d e ~ C a e n ~ N o r m a n d i e, ~ U M R ~} 6552$ laboratoire d'éthologie animale et humaine, Rennes, France.

${ }^{\text {b }}$ CNRS, UMR 6552 Université de Rennes, Université de Caen Normandie, laboratoire d'éthologie animale et humaine, Rennes, France

${ }^{1}$ Present address : Université Clermont Auvergne, INRAE, VetAgro Sup, UMR Herbivores, F-63122 Saint-Genès-Champanelle, France.

*Corresponding author: S. Lumineau, UMR CNRS 6552 Ethologie Animale et Humaine, Université de Rennes I, Bâtiment 25, Campus de Beaulieu, 263 Avenue du Général Leclerc, CS74205, 35042 Rennes, France.

e-mail address: sophie.lumineau@univ-rennes1.fr

\section{Highlights:}

- Our subjects were quail that bred fostered chicks of either stressed or non-stressed females 
- Chicks of stressed females solicited more their adoptive mother

- Adoptive mothers remained closer to chicks of stressed females, aggressed and rejected them less

- Adoptive mothers reacted more to separation from their chicks

\begin{abstract}
Beyond the genetic links between mother and young, prenatal effects experienced by offspring can modulate their mother's behaviour and stress. Here we investigated the consequences of stress-induced prenatal maternal effects on quail chicks' behaviour and maternal behaviour. We evaluated how adoptive quail mothers (unstressed) raised chicks of females that had either been stressed (PS) or were non-stressed (NPS) during laying. We demonstrated previously that our social stress procedure during laying increases levels of egg yolk steroid and chicks' emotional reactivity during the postnatal period. We found that, compared to NPS mothers, PS mothers remained closer to their chicks, were aggressed and neglected them less, emitted more maternal vocalisations and called their chicks more when they were separated. Moreover, PS chicks made more requests on their mother. Our results show that mothers responded to chicks' behavioural changes caused by prenatal stress by adapting their maternal behaviour. As exemplified here, for the first time in birds, prenatal environment can affect postnatal maternal behaviour by changing their offspring's behaviour.
\end{abstract}

KEYWORDS: prenatal stress; maternal behaviour; aggressiveness; mother-young relationship; epigenesis.

\title{
1. INTRODUCTION
}


Individual development is built from a genetic base interacting with environmental effects. Environmental effects, especially maternal effects, can act during the postnatal period as well as during prenatal development. Female mammals' environment is known to have a prenatal maternal influence. Stressful events modulate the chemical gestational milieu which modulates, in return, several physiological and behavioural traits of offspring: growth, sexual development and dimorphism, anxiety and social behaviour, and learning and memory abilities (for reviews: Brunton, 2013; Weinstock, 2008). Oviparous species are also sensitive to prenatal environmental effects, such as the effects of changes in temperature or changes in light exposure on eggs during incubation ((Dadda and Bisazza, 2012; Murray and McPhail, 1988; Riedstra and Groothuis, 2004; Romanoff, 1936; Roosenburg and Kelley, 1996). However, these effects can also act before egg-laying. In the same way, female birds' environment also acts as a prenatal influence by modulating females' hormone deposition in eggs, which has implications for offspring's subsequent phenotype. Several experiments illustrate these points by direct injection of hormones into eggs (for review Groothuis et al., 2005), and, more recently, by direct modulation of maternal environment. Social and physical perturbations during the laying period increased testosterone levels in quail's egg yolk, and chicks hatching from these eggs expressed higher emotivity in a novel environment and in social isolation (Guibert et al., 2011, 2010). On the other hand, female quail's positive interactions during the laying period produced less emotive and more social offspring (Le Bot et al., 2014). Particular attention has been paid to the influence of these hormonal modulations on the begging behaviour of altricial bird nestlings (for review Smiseth et al., 2011). For example, canary chicks from eggs with higher concentrations of testosterone spent more time begging than chicks from control eggs (Schwabl, 1996). Prenatal environmental effects can therefore influence offspring's behaviour towards their parents. 
Parental behaviour, in particular maternal behaviour, varies between species, but also between individuals of the same species (Fairbanks, 1996; Pittet et al., 2013). Differences in quality of mothering profiles are called maternal styles. They are particular to each female and remain consistent over several periods of maternal care (Fairbanks, 1996). Maternal styles are of primates (Maestripieri, 1993) and rodents (Liu et al., 1997) are well known and have been demonstrated recently in birds (Pittet et al., 2014a). Several factors are known to influence the quality and the quantity of care provided by mothers, such as their maternal experience (Maestripieri, 2005; Pittet et al., 2013), age (Pittet et al., 2012) or individual temperament (Huver et al., 2010; Pittet et al., 2014b).

Parents can adjust their behaviour to the specific needs of their young according to their sex or their condition for instance (Aigueperse et al., 2019, 2018; Stěhulová et al., 2013; White et al., 2007). Parents can respond by providing more efficient developmental conditions, thereby optimising their parental investment (Kölliker and Richner, 2001). Thus offspring's behaviour is a cue expressing their needs, and authors believe that these requests can control maternal behaviour directly (Kilner and Johnstone, 1997). Evidence shows that the behaviour of the offspring of several species of mammals and even insects influences their parents' maternal behaviour (Kober et al., 2008; Mas and Kölliker, 2008; Meek et al., 2001a). Altricial bird parents, such as pigeons (Mondloch, 1995) and canaries (Kilner, 1995), supply their young with more food when they solicit more care or beg more.

Factors of environmental prenatal effects and the response of mothers to their offspring's behaviour can interact. As previously described, environmental prenatal effects can influence maternal behaviour. The literature shows that prenatal stress modifies rodents' maternal behaviour via biochemical modifications (Power and Moore, 1986) and/or via modification of offspring's behaviour (Maccari et al., 1995). For example, prenatally stressed pups, raised by either stressed or unstressed mothers received less direct or indirect maternal care due to less 
pup activity and requests (Pérez-Laso et al., 2013; Power and Moore, 1986). Most of these investigations involved cross-adoptions that enable discrimination between maternal care delivered by stressed/non-stressed biological mothers and by stressed/non-stressed adoptive mothers. Nevertheless, despite numerous studies of rodents and a new demonstration in insects (Paquet and Smiseth, 2017), no experimental evidence exists for birds. This is why we investigated the effects of prenatal environment, through social stress of laying quail, on chicks' and mothers' behaviour.

Japanese quail Coturnix c. japonica, is a particularly relevant model for studying prenatal effects. This species can be raised without a mother, without developing severe physiological or behavioural deficits compared to altricial birds or to mammals (Pittet et al., 2013). Having the ability to adopt chicks to different mothers allows us to exclude the effects of genetic influences during maternal care. Previous studies(Guibert et al., 2013, 2011, 2010) showed that in the absence of maternal care, females stressed during egg laying produce eggs with more testosterone and their chicks were more emotional. This allowed us to hypothesize that chicks of mothers stressed during laying would solicit their adoptive mother more because of increased testosterone levels in the eggs, as in altricial birds (Smiseth et al., 2011). We also hypothesized that mothers would respond to the increase in these requests by increasing maternal care, as rodents(Moore and Power, 1986; Pérez-Laso et al., 2013). Thus, we hypothesized that an environmentally induced prenatal parental effect would have a direct influence on a precocial bird species' maternal behaviour.

\section{METHODS}

2.1.Prenatal Treatment via Social Instability Procedure of Laying Female 
Our subjects were 100 Japanese quail females from an industrial farm (Les cailles de Chanteloup, France). Groups of 5 6-week-old females were placed in 20 cages $(100 \mathrm{~cm} \times 70 \mathrm{~cm} \times 62 \mathrm{~cm})$ in a single room, exposed to a LD 14:10 cycle and to a temperature of $20 \pm 1{ }^{\circ} \mathrm{C}$ (humidity $50 \%$ ) with food and water ad libitum. After 6 weeks of habituation to these living conditions, we divided them randomly into two sets: 10 groups were socially stressed and 10 others were not stressed. We followed the procedure described by Guibert et al. (2010) to induce social instability. This procedure is known to induce more aggressive behaviours and an increase of females' corticosterone levels. We exchanged 2 females between cages in the stressed cages, every four days. At a same time, we took 2 females out of the non-stressed cages but we replaced them in the same cage, to control the effects of handling. We performed four exchange stress sessions and then we evaluated instability (increasing of females' aggressively). Mating occurred the day following each instability change. All females met a male that was assigned randomly to a group of females. One male was assigned to two groups (one per treatment) of females and met them alternately. First, each male was placed in a small circular cage in the females' room, and then all females of one group were placed one by one with him until we observed successful copulations. Eggs were collected daily for 2 weeks and incubated artificially for 17 days $\left(37.7^{\circ} \mathrm{C}, 55 \%\right.$ of humidity and two $45^{\circ}$ rotations/day). Egg mass and hatchability did not differ significantly between the two groups.

Hatching was synchronized for chicks: only those born on the same day were used for the experiment. When chicks hatched, they were placed in plastic boxes $(98 \times 35 \times 42 \mathrm{~cm})$ in groups according to their mother's cage, with a heater $\left(40 \pm 1^{\circ} \mathrm{C}\right)$ and food/water ad libitum, until the evening (adoption). As we cannot determine the sex of the chicks just after hatching, we sexed them when they were 6 weeks old, when sexual dimorphism appears clearly. However, the sex ratio did not differ between groups $\left(\chi^{2}=0.51, \mathrm{P}=0.48\right)$. Chicks were weighed at hatching and at the end of the mothering period (11 days). At hatching, PS chicks were heavier than NPS chicks 
$\left(\mathrm{NPS}=9.8 \pm 0.1 \mathrm{~g}, \mathrm{PS}: 10.3 \pm 0.1 \mathrm{~g} ;\right.$ ANOVA: $\left.\mathrm{F}_{1,189}=14.86, \mathrm{P}<0.001\right)$ agreeing with Guibert et al.'s (2010) previous report. Nevertheless, when we placed chicks with mothers, the weights of the experimental individuals were homogeneous between groups (NPS $=10.0 \pm 0.2 \mathrm{~g}, \mathrm{PS}=$ $10.2 \pm 0.2 \mathrm{~g}, \mathrm{p}==0.35$ ). Body weights did not differ significantly between the two groups at 11 days $(\mathrm{NPS}=49.9 \pm 3.5 \mathrm{~g}, \mathrm{PS}=54.9 \pm 1.9 \mathrm{~g}, \mathrm{p}=0.12)$.

\subsection{Fostering Procedure}

Twenty-four females from the same commercial line, and not directly related to the chicks, were placed in individual cages $(51 \mathrm{~cm} \times 40 \mathrm{~cm} \times 35 \mathrm{~cm})$ in a single room. Indeed, in the field, females remain alone while caring for their chicks (Orcutt and Orcutt, 1976). We divided the females randomly into two groups: 12 females (NPS-m) each adopted 3 chicks from different non-stressed females (NPS-c) and 12 females (PS-m) each adopted 3 chicks from different stressed females (PS-c). None of the chicks in a group came from the same adult female group so that (1) all adult female groups were represented equally and (2) none of the three chicks in a group came from the same mother group. The cages had grid floors and doors, metallic opaque lateral walls and contained feeding troughs $(50 \mathrm{~cm}$ long) and a drinking bottle near the door. They were placed alternatively in the room maintained under a LD $12: 12$ cycle and at $23 \pm 1^{\circ} \mathrm{C}$. This adoption procedure is adapted from Richard-Yris (1994). The evening adoption was initiated, before the lights were switched off, fostering mothers were placed in a plastic nestbox $(18 \mathrm{~cm} \times 18 \mathrm{~cm} \times 18 \mathrm{~cm})$ for one hour in their cage. Then, we delicately placed 3 chicks under each female in her nestbox. Tactile and audible stimulations by chicks facilitate fostering by quail (Richard-Yris, 1994). The next morning, we opened and removed the nestboxes from the cages and we checked whether induction of maternal behaviour had been successful. We monitored chicks by looking for signs of discomfort and hypothermia (trembling, motionless, closed eyes). Any chick that showed any of these signs was removed and placed in a plastic cage $(98 \times 35 \times 42 \mathrm{~cm})$ under a heater where it recovered quickly. We 
verified that mothers provided effective maternal care during all the first morning following adoption (PHD2 = Post-Hatching Day): 8 NPS-m and 11 PS-m females performed maternal behaviours after induction, presenting few unadapted behaviours (aggression) and no or bad warming postures. So we had to discard five females from this experiment (4NPS-m, 1PS-m) because induction had failed (no maternal behaviour). However, two NPS mothers had to be removed from this experiment, one on PHD6 and one on PHD10, because they had become too aggressive. Otherwise, chicks that had to be removed were replaced by chicks of the same age and placed near the mothers throughout the experiment, but after 3 days of mothering, substitute chicks (10 NPS-c and 6 PS-c) were not taken into account for observations and behavioural tests.

When chicks were 11 days old, mothers were removed and placed in another room in groups while chicks stayed with siblings in their cages for 4 more weeks.

\subsection{Behavioural Observations of Mothers and Chicks}

The observation protocol and the ethogram are adapted from Pittet and collaborators (2013). Two methods were used: focal sampling to record infrequent behaviours and instantaneous scan sampling to determine time-budgets. Data were collected live by one observer for both methods, blind to the treatment, twice a day (morning and afternoon). Each session recording mothers' behaviour started by scanning their behaviour followed by focus observations. These records were made on PHD2 (only afternoon), PHD3, PHD5, PHD7 and PHD9. Chicks' behaviour was scanned on PHD4 and PHD10.

\subsubsection{Instantaneous scan sampling}

Thirty scans of each mother were recorded during a session alternating between NPS and PS mothers, using an ipod Touch (Apple(C) equipped with the application "scan sampling" (Vincent Richard(C). We recorded, for each female her general behaviour: rest, eat, explore, 
preen, observe (mother remains still, not walking or in a warming posture, eyes open), peck (mother stands still and pecks at a chick near her) or attack (mother chases a chick and pecks it) and warm chicks. When a mother was warming chicks we specified her posture: covering chicks completely (the most efficient) or not. We recorded distance between mother and chicks: close (chick is not under its mother but in contact with her), near (chick is at one chick-length from mother), far (chick is between one chick-length and two chick-lengths), far away (chick is between two chick-lengths and half the cage) and opposite (chick is more half cage from mother).

Thirty scans of chicks were recorded during two sessions (morning and afternoon) on PHD4 and on PHD10. We recorded, for each chick their general behaviour: rest, eat, explore, preen, observe, walk. When chicks were resting, we recorded whether they were being warmed or resting alone. We also recorded when chicks escaped from mother (after a peck, an attack or just an approach of mother), distress calls and requests. Request means that chicks peck their mother's feathers gently and/or push them to slip under their mother. Activity is calculated based on data for all active behaviours excluding observe, rest alone or being warmed.

\subsubsection{Focal sampling}

Each female was observed for $5 \mathrm{~min}$ during each session in a random order with one condition: to alternate between NPS and PS treatments (so sequences were determined by an experimenter other than the observer). Occasional behaviours were recorded, such as maternal vocalisations (cooing, call cries, and food calls), number of times chicks requested, were trampled and number of contact breaks between mother and chicks, and who initiated them. 2.3.3. Reaction to separation 
On PHD11, chicks were removed from their cage and we observed the reactions of the mothers during $5 \mathrm{~min}$. We recorded latency of comfort behaviour (feeding, rest, and maintenance), high observation postures (erect posture of the subject, but not tense), and latency and number of vocalisations (distress calls). The females were tested one by one. After each observation, the test mother was placed with her chicks in another room until the end of all the test sessions.

\subsection{Statistical Analyses}

We computed a principal component analysis (PCA) with the main variables of mothering and general activities of the mothers for each observation day. We used a varimax rotation to maximise graphical independence between the components (maximisation to the sum of the variances of the squared loadings and leaving the sub-space invariant), and we chose a criterion of PC loading of $|0.5|$ or higher to consider that a variable was relevant to a specific component (Abdi, 2003). Factorial scores on each PCA axis and weights were then examined with linear mixed models on repeated measures (LMMr) after logit transformation if there was a lack of normal distribution of residuals: treatments (NPS and PS), time and their interactions were used as fixed factors. Post-hoc comparisons were made by LSD tests (Least Significance Difference - Fisher tests). Maternal vocalisations, not included in PCA because of their rarity, were analysed with generalized linear models (GLM), day by day using the Poisson error distribution. Variables of separation data were compared with GLM, using Gaussian distribution for continuous variables and Poisson distribution for occurrences.

A second PCA with varimax rotation evaluated chicks' behaviour. We compared factorial scores calculating a linear mixed model with repeated measures (LMMr) where time, treatment and their interactions were studied as fixed factors and mothers' and chicks' identities were considered as a random factor. We performed post-hoc comparisons by LSD tests. 
The threshold of significance was 0.05. PCA were computed with XLSTAT 3.0 (@)Addinsoft

2011) and data were analysed with SPSS 20 (@IBM.).

\subsection{Ethical Note}

All experiments were approved by the departmental direction of veterinary services (Ille-etVilaine, France, permit number 005283) and were performed in accordance with the European Communities Council Directive of 22th September 2010 (2010/63/EU). Our breeding procedure and tests were approved by the regional ethics committee (agreement number: R2011-SLU-02). We have reduced the number of animals, enriched the cages and avoided any injuries.

During the social instability procedure, intrusion of unfamiliar females into a social group increased aggression between animals. Nevertheless none of the subjects were injured because they could hide under opaque shelters in the cages.

During the mothering period, we reduced as much as we could the number of subjects involved. As some females failed to adopt chicks, 24 was the minimum sample size needed to obtain robust statistical results. We used a brood size of three chicks as it is the smallest brood size that can elicit maternal care.

Adult females were housed singly because they generally stay alone while they incubate and care for their chicks(Orcutt and Orcutt, 1976). Housing females singly is consequently the usual laboratory procedure for breeding experiments (Houdelier et al., 2011). Remark that they stayed in auditory contact as they were in the same room. We did not provide hiding places because we had to be able to observe them continuously to estimate interindividual distances and mother/chicks interactions. Nevertheless, observations were made behind one-way mirrors so that birds would not to be disturbed by our presence. We checked that the females showed no 
stereotypies, distress calls or flight attempts, and that they performed comfort behaviours such as dust bathing, which was facilitated by plastic netting covering the cage floor and a box (20 x $20 \times 6 \mathrm{~cm}$ high) with wood shavings. We removed this box in presence of chicks to avoid injuries or brooding problems.

During all the mothering period, we paid much attention to the possible emergence of aggressive behaviours and neglect. As soon as a chick showed signs of hypothermia (trembling, motionless, closed eyes), it was removed and replaced by another chick. Aggressive behaviours indicate maternal rejection, but they were only very occasional and never caused any injury. If a mother's rejection persisted and emitted vocalisations such as their 'threat' vocalisations and their chicks emitted loud vocalisations, we removed the chicks immediately. These chicks were then put under a heater in a plastic cage $(98 \times 35 \times 42 \mathrm{~cm})$. Chicks that showed signs of hypothermia swiftly recovered (in less than $1 \mathrm{~h}$ ). In all 26 chicks had to be replaced: 10 before PHD3 (6NPS and 4PS) and 16 after PHD3 (10 NPS and 6 PS). No mortality was recorded. We kept these birds for further experiments.

\section{RESULTS}

\subsection{Maternal Care}

\subsubsection{Maternal behaviour}

A PCA on maternal behaviour data revealed three components with eigenvalues greater than one, which together explained $66.86 \%$ of the variance (Fig. 1). We named the first component (28.95\%) "Warming \& Distance" represented by percentage of warming time versus motherchick distance, with negative and positive loadings, respectively. The second component (19.19\%), named "Activity", had positive loadings for activity and maintenance. The third component (18.72\%) was labelled "Rejection \& Aggression" with positive loadings for 
mothers' contact breaks, negligence behaviours like trampling or aggressive behaviours towards chicks.

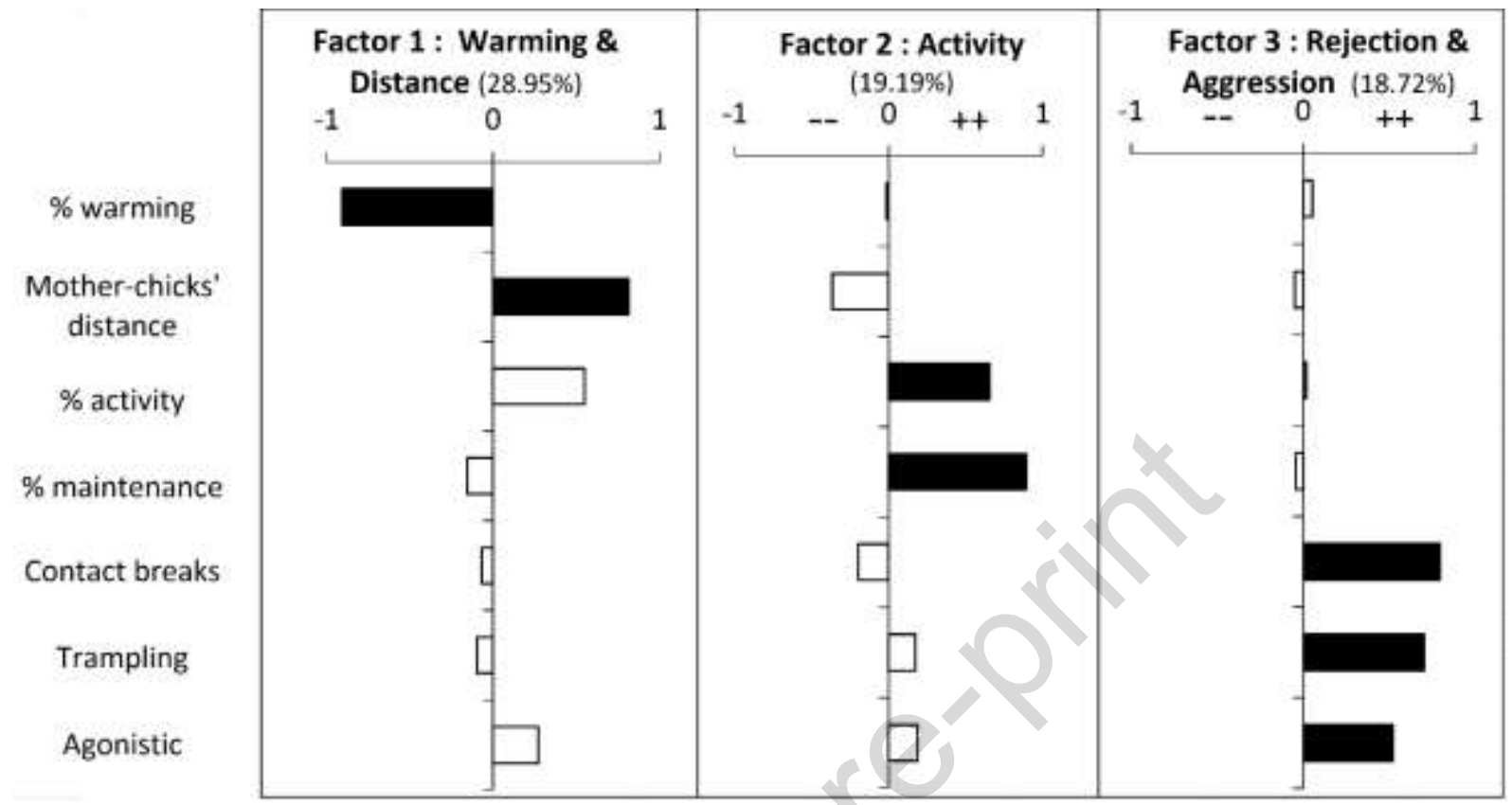

Figure 1: Mothers' behaviour during the mothering period described by the seven main behavioural variables on the first three axes of PCA with varimax rotation. The first factor represents warming versus mother-chick distances. The second represents the level of mothers" activity: "--"= female resting, "++"= active female. The third factor represents the level of mothers' rejection and aggression towards chicks: “--“= low rejection \& aggression, " $++"=$ high rejection \& aggression.

LMr comparisons of scores of females on these three PCA components revealed a time effect on Warming \& Distance and Activity (Warming \& Distance: $\mathrm{F}_{4,95}=23.70, \mathrm{P}<0.001$; Activity: $\mathrm{F}_{4,95}=20.89, \mathrm{P}<0.001$ ), but not on Rejection (Rejection: $\mathrm{F}_{4,95}=1.31, \mathrm{P}=0.27$ ). With time, mother brooded less and kept greater distances from their chicks. Post-hoc LSD by day indicated that PS-m were significantly less active on PHD7 $(\mathrm{P}<0.05)$. We observed a treatment effect on Warming \& Distance $\left(\mathrm{F}_{2,98}=4.35, \mathrm{P}<0.05\right)$ and Rejection $\left(\mathrm{F}_{2,98}=5.00, \mathrm{P}<0.05\right)$ but not on Activity ( $\left.\mathrm{F}_{2,98}=3.01, \mathrm{P}=0.09\right)$ (Fig. 2): PS-m generally remained closer to chicks, warmed them 
more, aggressed/neglected them less. We could not evidence any timextreatment interaction effects (Warming \& Distance: $\mathrm{F}_{11,80}=1.05, \mathrm{P}=0.39$; Activity: $\mathrm{F}_{11,80}=1.26, \mathrm{P}=0.29$; Rejection: $\mathrm{F}_{11,80}=0.34, \mathrm{P}=0.85$ ). (Fig. 2).

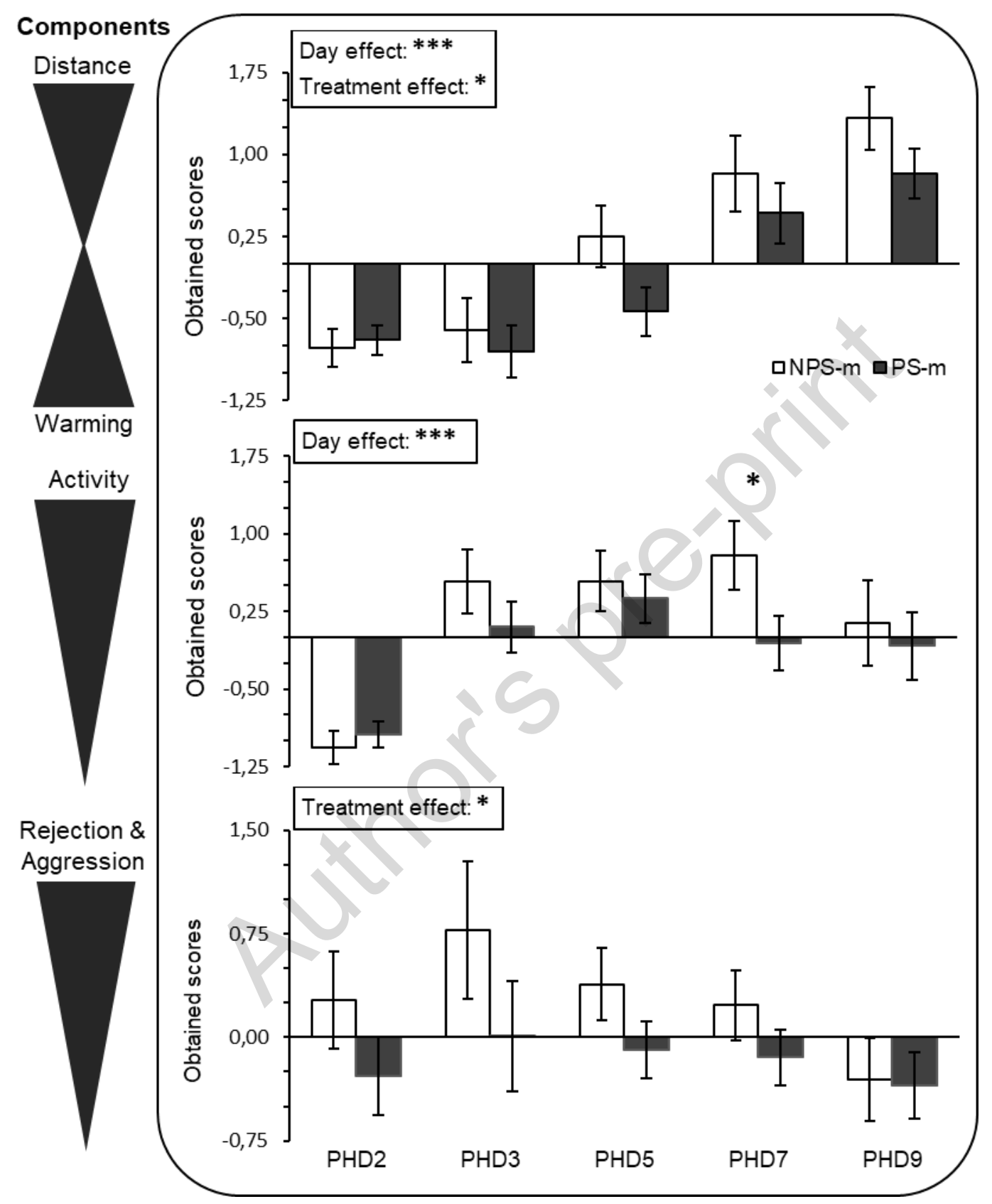

Figure 2: Scores (mean $\pm \mathrm{SE}$ ) on the PCA three components "Distance/warming", "Activity" \& "Rejection \& aggression", by day, for NPS-m (black bars) \& PS-m (white bars). Boxed texts give the main results of LMMr tests (other effects were not significant). The results of post-hoc LSD are on the graph: \#: $\mathrm{P}<0.10, *: \mathrm{P}<0.05$. 


\subsubsection{Maternal vocalisations}

PS-m females emitted more maternal vocalisations than did NPS-m during all the mothering period (GLM, PHD3: $\mathrm{F}_{2,17}=5.23, \mathrm{P}<0.05$; PHD5: $\mathrm{F}_{2,17}=7.64, \mathrm{P}<0.05 ;$ PHD7: $\mathrm{F}_{2,16}=7.39$, $\mathrm{P}<0.05$; PHD9: $\mathrm{F}_{2,16}=5.53, \mathrm{P}<0.05$ ), except on PHD2 when no female vocalised (Fig. 3).

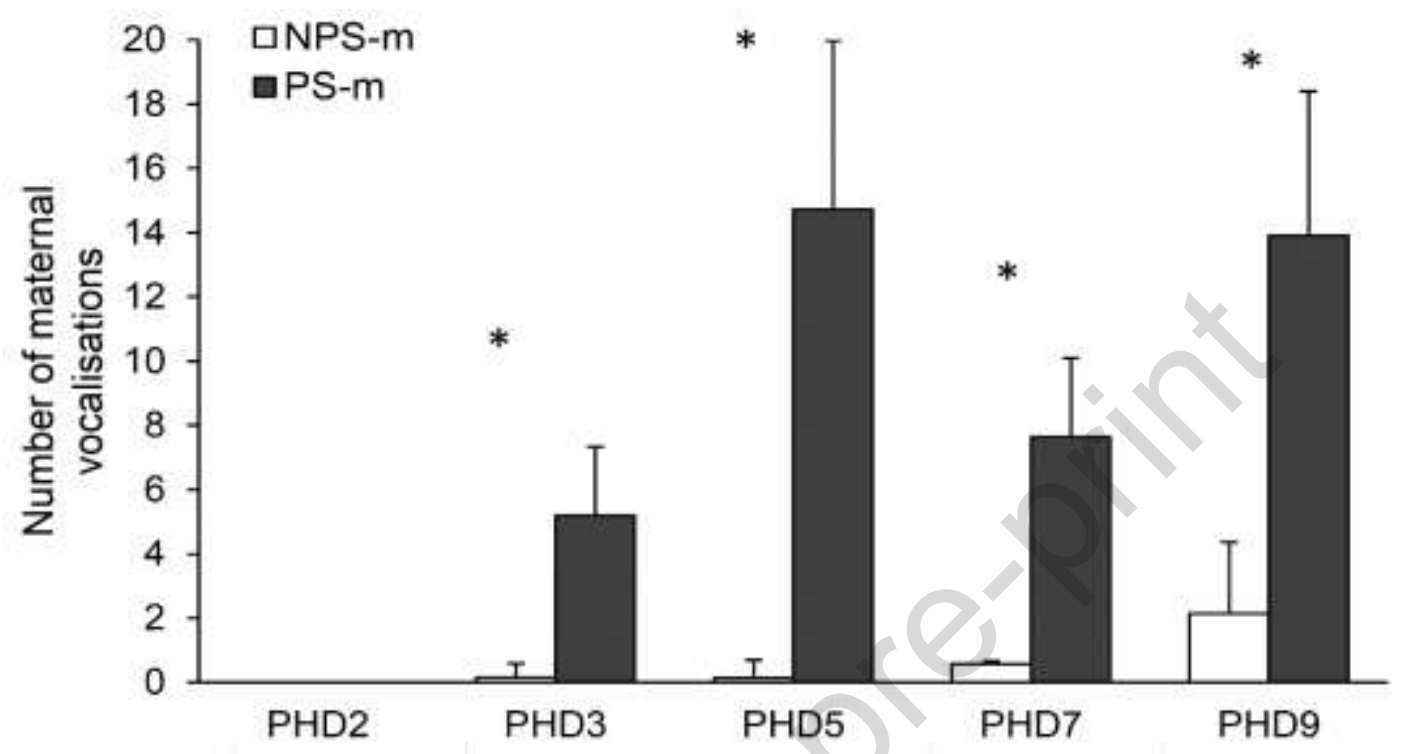

Figure 3: Maternal vocalisations (mean+SE) emitted during 10 min focusing sampling on PHD2, PHD3, PHD5, PHD7 and PHD9 by groups of prenatally stressed (PS-m) and non-prenatally stressed (NPS-m) mothers. GLM tests: $*=\mathrm{P}<0.05$.

\subsubsection{Reaction to separation}

PS-m seemed to be more affected by separation from their chicks as they were observed more frequently in high observation postures $\left(\mathrm{F}_{2,15}=5.30, \mathrm{P}<0.05\right)$, and delayed more initiating comfort behaviours than did NPS-m $\left(\mathrm{F}_{2,15}=6.90, \mathrm{P}<0.01\right)$. Moreover PS-m delayed calling longer following separation $\left(\mathrm{F}_{2,15}=58.09, \mathrm{P}<0.001\right)$ but then called more frequently than NPS$\mathrm{m}\left(\mathrm{F}_{2,15}=25.96, \mathrm{P}<0.001\right)$ (Fig. 4). 


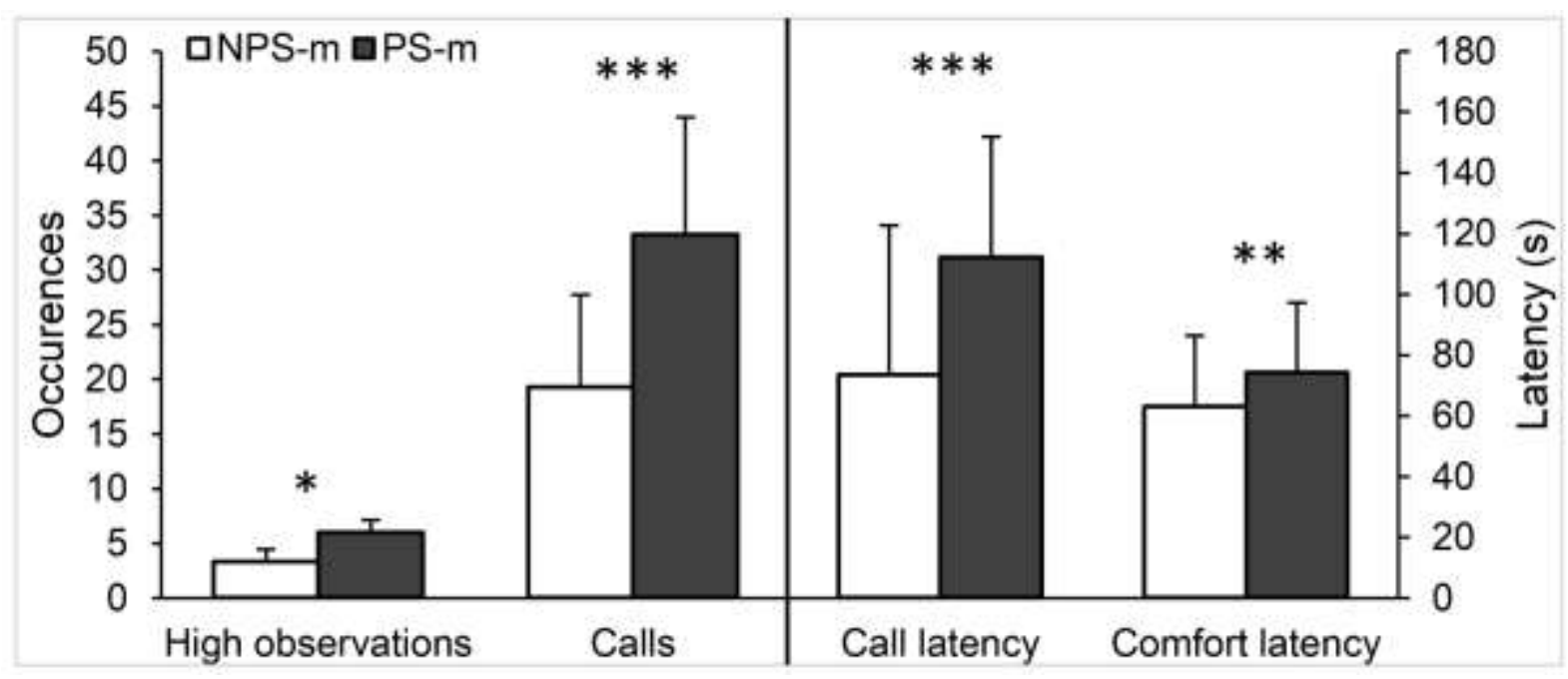

Figure 4: Mothers' high observation positions, calls and latencies to call and to comfort (mean+SE) following mother-chick separation (PHD11, 5min of FOCUS) for the groups of prenatally stressed PS-m and non-prenatally stressed NPS-m mothers. GLM tests: $*=\mathrm{P}<0.05, * *=\mathrm{P}<0.01 \quad \& * * *=\mathrm{P}<0.001$.

\subsection{Chicks' Behaviour}

A PCA analysis revealed two components with eigenvalues greater than one that explained $61.96 \%$ of the variance (Fig. 5). The first component (32.41\%) was represented by chicks' activity (negative loading) versus warming (positive loading). We named the second component (29.55\%) "No interactions with mother", as it had negative loadings for distress behaviours represented by "escape" and "call cries" and positive loadings for warming requests. 


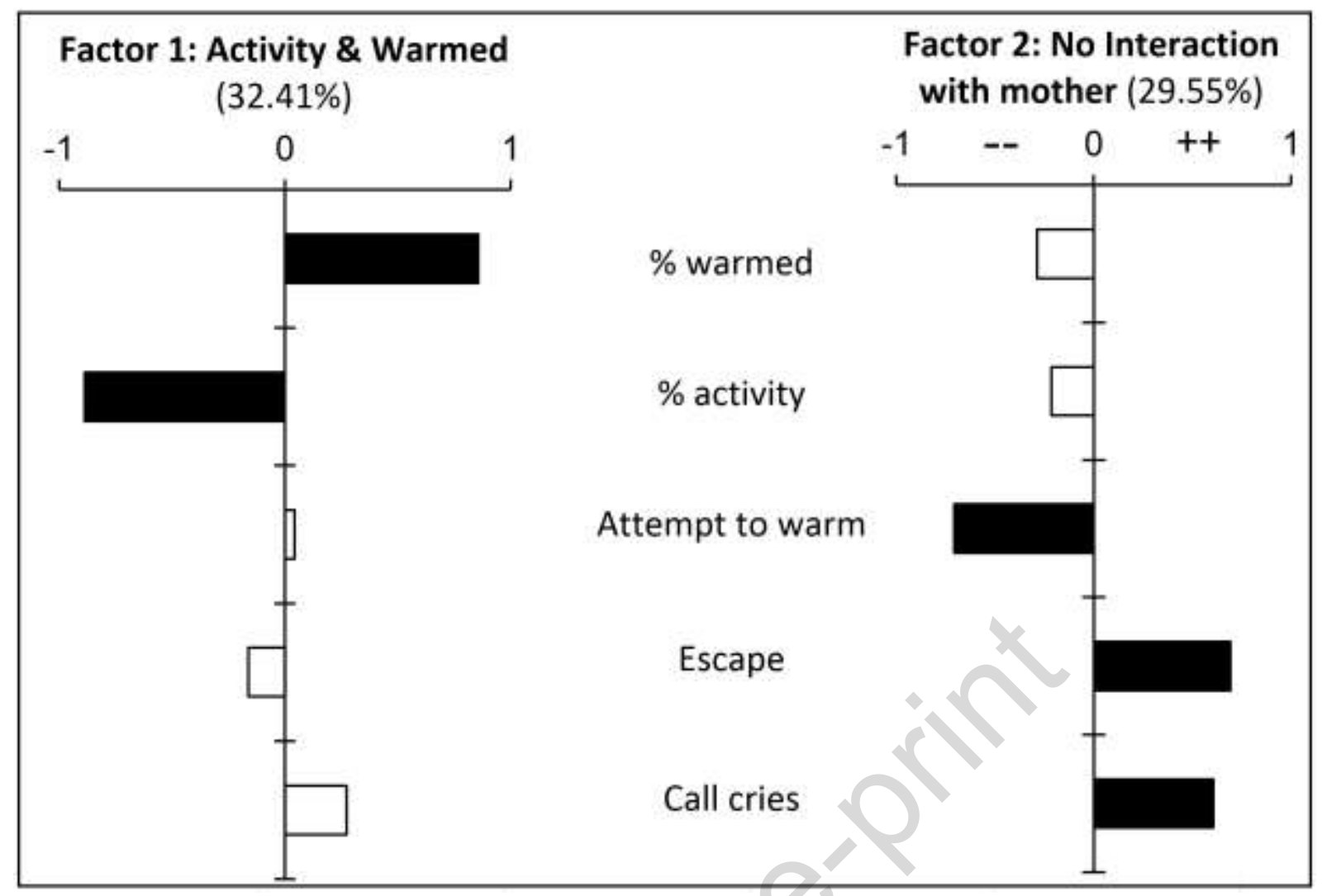

Figure 5: Chicks' behaviour during the mothering period described by the five main behavioural variables on the first two components of the PCA with varimax rotation. The first component represents chicks' activity versus warming. The second reflects interactions with mother, with requests versus distress behaviours.

LMMr comparisons of scores obtained by chicks (Fig. 6) revealed a time effect on the “Activity/Warming" component $\left(\mathrm{F}_{3,164}=88.5, \mathrm{P}<0.001\right)$ with more warming at the beginning and more activity to the end of the experimental period, and a treatment effect on the "Interactions with mother" component $\left(\mathrm{F}_{3,164}=3.22, \mathrm{P}<0.05\right)$ : NPS-c expressed distress more whereas PS-c solicited their mothers more for warming (Fig. 6). No other effects were significant. 


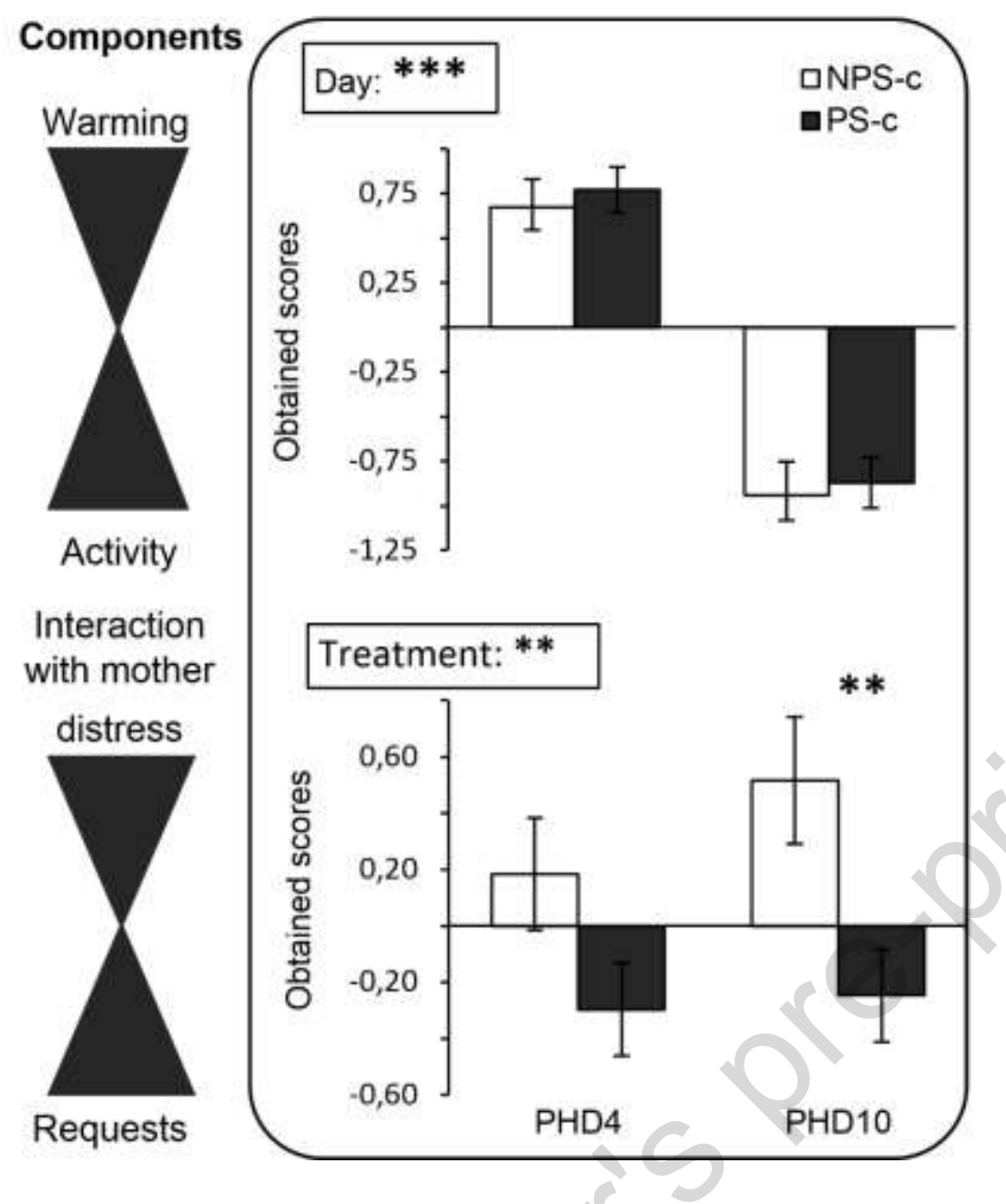

Figure 6: Chicks' scores (mean \pm SE) on the two components "Warming/Activity" \& "Interaction with mother", by day, for NPS-c (black bars) \& PS-c (white bars). The boxes give the general significant results of the LMMr test (other effects were not significant) and the results of Post-hoc LSD are on the graph: \#: $\mathrm{P}<0.10 \& * *$ : $\mathrm{P}<0.01$.

\section{DISCUSSION}

Our results revealed a modulation of maternal care according to the prenatal conditions of chicks: foster mother quail performed more maternal care when they raised chicks from females that had been stressed during laying.

We demonstrate here that PS-m mothers were more maternal (less negligent/aggressive) and vocalised more in response to PS-chicks' requests during all the mothering period, and after 
separation. Vocalisations play a role both in maintaining the family unit and in helping reduce stress. Edgar et al. (2011) established that hens emitted more vocalisations when their chicks were stressed. Quail could also feel the higher concern of their chicks. These authors argue that hens are able to react when they observe their chicks receiving an aversive stimulus and thereby have one of the essential underlying attributes of empathy, defined by the capacity to be affected and to share the emotional state of a conspecific (Preston and de Waal, 2002). This hypothesis could possibly be supported by our results but requires to further investigation.

In addition to chicks' direct requests, another mechanism could influence maternal behaviour. Recent studies show that mother hens secrete an odorant (Mother Hens' Uropygial Secretion Analogue) that has an appeasing and attractive effect on chicks, thus proving that they are sensitive to maternal odours (Madec et al., 2008). We hypothesise that a reciprocal effect exists and mothers could be sensitive to odours or compounds released by chicks. Testosterone levels of prenatally stressed rat pups are first higher then lower during foetal development than non prenatally stressed pups and this would induce mothers to lick their ano-genital area less (Moore and Power, 1986). Prenatal stress increases testosterone levels in quail's egg yolks (Guibert et al., 2010) and thereafter chicks excrete more corticosterone, a stress hormone, and testosterone, after a stressor (Daisley et al., 2005). Mothers could then be more sensitive and therefore more responsive to these chicks that, in turn, remain closer to their mothers than do controls chicks. Moreover, altricial birds' maternal hormones as a whole are also known to influence chicks begging (Smiseth et al., 2011) although the underlying mechanisms are not yet well-known their influence could be similar in precocial birds.

We also showed that adoptive mothers rejected less chicks from stressed females. Previous studies demonstrated that quail mothers present, between PHD5 and PHD7, an "emancipatory rejection" behaviour, which stimulates chicks' independence (Aigueperse et al., 2017): mothers reject their chicks and become more aggressive when their chicks insistent on remaining close 
to their mother. Here, we found a similar pattern for NPS-m mothers but not for PS-m mothers that never expressed this "emancipation rejection" during the 11 days of the mothering period and appeared to stimulate their chicks' independency only later. Therefore, these mothers provided more maternal care and for longer. Although factors influencing duration of birds'maternal care have not been investigated for birds, authors report the opposite effect for rodent mammals: prenatally stressed pups, raised by stressed or unstressed mothers received less maternal care (Meek et al., 2001; Pérez-Laso et al., 2013; Power and Moore, 1986). Several reports show that offspring's behaviour influences the quality and the quantity of maternal care they receive. As mother-offspring interactions are often dynamic, a mother responds more when her offspring solicit her more, as for instance do parent birds to their chicks' begging (Kilner and Johnstone, 1997a; Meek et al., 2001). Quail's maternal behaviour is stimulated more by tactile and auditory stimuli than by visual stimuli (Richard-Yris and Leboucher, 1987). Therefore, direct contact with their mother, especially ventral contact, is important as it influences the levels of her hormone such as prolactin, oestradiol and luteinising hormones, which play an important role in the establishment and maintenance of maternal behaviour (Leboucher et al., 1990). We suggest that under their mother, stimulations provided by PS chicks could be stronger, but this hypothesis remains to be validated. In this sense, we found that PS chicks solicited warming by their mothers more frequently, particularly during the second half of the mothering period, whereas NPS chicks avoided their mothers and emitted more distress calls. Increasing numbers of requests stimulates altricial birds and some species of insects to feed their offspring more (Agrawal et al., 2001; Kilner and Johnstone, 1997).

Prenatal and postnatal effects could be a way for parents to prepare offspring to face postnatal environmental challenges (review: Houdelier et al., 2013). For instance, prenatal stress generally stimulates and increases mammals' (Kaiser and Sachser, 2005) and birds' (Guibert et al., 2010) fear in the presence of stressful events. Parents can modulate chicks' behavioural 
traits through postnatal experience (Desmedt et al., 2020; Galuret et al., 2020; Pittet et al., 2019, 2014c). Mothers can thus transmit part of their own behavioural characteristics by non-genetic pathways, like their feeding preferences (Wauters et al., 2002) or their social or emotional behaviour (Formanek et al., 2008; Richard-Yris et al., 2005). However, a better understand their adaptive roles must now include interactions between prenatal and post-natal effects. In particular, studies have shown that a mismatch between prenatal and postnatal conditions cause negative effects on offspring's development. For instance, a mismatch between pre- and postnatal nutritional conditions induces health problems in sheep (Ovis aries) offspring, whereas no such effects are observed when pre- and postnatal food conditions match (Cleal et al., 2007). Then, if environmental conditions change, mothers' possibility to adjust offspring's phenotype after birth could mitigate prenatal effects. Prenatally stressed rodent pups, raised by either stressed or unstressed mothers, received less direct or indirect maternal care (Moore and Power, 1986; Pérez-Laso et al., 2013). Canary (Serinus canaria domestica) mothers modified their offspring's post-hatching food begging, likely through differential allocation of androgens to eggs, to match their own foraging capacity (Hinde et al., 2009). These interactions between pre- and post-natal conditions could drive adaptive phenotypic plasticity, creating responses that could promote adaptation to changing environments and future evolution, but are still poorly investigated.

\section{CONCLUSION}

To conclude, sensory stimulations emitted by chicks can influence their mother's behaviour that in turn influences her chicks either by keeping them close to her or not, thereby modulating the stimuli sent back to their mother. This can modify the timing of mothering and delays a mother's emancipatory rejection stimulating chicks' independency. So, it appears that female 
quail can be influenced by, and react to, their chicks' phenotype, and maybe even to their emotional state, feeling their stress, this trait being one of the essential characteristics of empathy (Preston and de Waal, 2002). Our experiment highlights, for the first time to our knowledge in a precocial bird species, the importance of prenatal environmental effects on maternal care and raises the question of a possible remediation of these prenatal effects, such as the weak growth and high emotivity reported by Guibert et al. (2010), through maternal readjustment of care. Our experiment stresses the importance when considering early living conditions of taking into account interactions with pre- and post-natal events to improve our understanding of the adaptation of individuals to their environment and its variations.

Credit author statement: Nadège Aigueperse : Data curation, formal analysis, writing original draft; Cécilia Houdelier: Conceptualization, Methodology, writing review and editing; Océane Le Bot: Data curation, writing review and editing; Emmanuel de Margerie: Methodology, writing review and editing; Sophie Lumineau : Conceptualization, Supervision.

6. Acknowledgements. We are most grateful to Ann Cloarec for her help with the English and C. Nicolle for taking care of birds. This work was supported by the French Agence Nationale de la Recherche (ANR) as part of the research project PReSTO'Cog (ANR-13-BSV7-0002).

\section{REFERENCES}

Abdi, H., 2003. Factor rotations in factor analyses. Encyclopedia for Research Methods for the Social Sciences. Sage: Thousand Oaks, CA 792-795.

Agrawal, A.F., Brodie, E.D., Brown, J., 2001. Parent-Offspring Coadaptation and the Dual Genetic Control of Maternal Care. Science 292, 1710-1712. https://doi.org/10.1126/science.1059910 
Aigueperse, N., Houdelier, C., Nicolle, C., Lumineau, S., 2019. Mother-chick interactions are affected by chicks' sex and brood composition in Japanese quail. Developmental Psychobiology. https://doi.org/10.1002/dev.21848

Aigueperse, N., Pittet, F., de Margerie, E., Nicolle, C., Houdelier, C., Lumineau, S., 2017. Brood size can influence maternal behaviour and chick's development in precocial birds. Behavioural Processes 138, 96-104. https://doi.org/10.1016/j.beproc.2017.02.018

Aigueperse, N., Pittet, F., Nicolle, C., Houdelier, C., Lumineau, S., 2018. Maternal care affects chicks' development differently according to sex in quail. Developmental Psychobiology 60, 1048-1056. https://doi.org/10.1002/dev.21597

Brunton, P.J., 2013. Effects of maternal exposure to social stress during pregnancy: consequences for mother and offspring. REPRODUCTION 146, R175-R189. https://doi.org/10.1530/REP-13-0258

Cleal, J.K., Poore, K.R., Boullin, J.P., Khan, O., Chau, R., Hambidge, O., Torrens, C., Newman, J.P., Poston, L., Noakes, D.E., Hanson, M.A., Green, L.R., 2007. Mismatched pre- and postnatal nutrition leads to cardiovascular dysfunction and altered renal function in adulthood. PNAS 104, 9529-9533. https://doi.org/10.1073/pnas.0610373104

Dadda, M., Bisazza, A., 2012. Prenatal light exposure affects development of behavioural lateralization in a livebearing fish. Behavioural Processes 91, 115-118. https://doi.org/10.1016/j.beproc.2012.06.008

Daisley, J., Bromundt, V., Möstl, E., Kotrschal, K., 2005. Enhanced yolk testosterone influences behavioral phenotype independent of sex in Japanese quail chicks Coturnix japonica. Hormones and Behavior 47, 185-194. https://doi.org/10.1016/j.yhbeh.2004.09.006

Desmedt, L., George, I., Benkada, A.M., Hervé, M., Aubin, T., Derégnaucourt, S., Lumineau, S., 2020. Maternal presence influences vocal development in the Japanese quail (Coturnix c. japonica). Ethology 126, 553-562. https://doi.org/10.1111/eth.13007

Edgar, J.L., Lowe, J.C., Paul, E.S., Nicol, C.J., 2011. Avian maternal response to chick distress. Proceedings of the Royal Society B: Biological Sciences 278, 3129-3134. https://doi.org/10.1098/rspb.2010.2701

Fairbanks, L.A., 1996. Individual Differences in Maternal Style: Causes and Consequences for Mothers and offspring, in: Jay S. Rosenblatt and Charles T. Snowdon (Ed.), Advances in the Study of Behavior, Parental Care: Evolution, Mechanisms, and Adaptive Significance. Academic Press, pp. 579-611.

Formanek, L., Houdelier, C., Lumineau, S., Bertin, A., Richard-Yris, M.-A., 2008. Maternal Epigenetic Transmission of Social Motivation in Birds. Ethology 114, 817-826. https://doi.org/10.1111/j.1439-0310.2008.01536.x

Galuret, S., Lumineau, S., Pouzol, D., George, I., 2020. Mothering influences domestic chick's laterality. Animal Behaviour 159, 69-79. https://doi.org/10.1016/j.anbehav.2019.11.005

Groothuis, T.G.G., Müller, W., von Engelhardt, N., Carere, C., Eising, C., 2005. Maternal hormones as a tool to adjust offspring phenotype in avian species. Neuroscience \& Biobehavioral Reviews, Prenatal Programming of Behavior, Physiology and Cognition 29, 329-352. https://doi.org/10.1016/j.neubiorev.2004.12.002

Guibert, F., Lumineau, S., Kotrschal, K., Möstl, E., Richard-Yris, M.-A., Houdelier, C., 2013. Trans-generational effects of prenatal stress in quail. Proc. R. Soc. B 280, 20122368. https://doi.org/10.1098/rspb.2012.2368

Guibert, F., Richard-Yris, M.-A., Lumineau, S., Kotrschal, K., Bertin, A., Petton, C., Möstl, E., Houdelier, C., 2011. Unpredictable mild stressors on laying females influence the 
composition of Japanese quail eggs and offspring's phenotype. Applied Animal Behaviour Science 132, 51-60. https://doi.org/10.1016/j.applanim.2011.03.012

Guibert, F., Richard-Yris, M.-A., Lumineau, S., Kotrschal, K., Guémené, D., Bertin, A., Möstl, E., Houdelier, C., 2010. Social Instability in Laying Quail: Consequences on Yolk Steroids and Offspring's Phenotype. PLoS ONE 5, e14069. https://doi.org/10.1371/journal.pone.0014069

Hinde, C.A., Buchanan, K.L., Kilner, R.M., 2009. Prenatal environmental effects match offspring begging to parental provisioning. Proceedings of the Royal Society B: Biological Sciences 276, 2787-2794. https://doi.org/10.1098/rspb.2009.0375

Houdelier, C., Lumineau, S., Bertin, A., Guibert, F., Margerie, E.D., Augery, M., RichardYris, M.-A., 2011. Development of Fearfulness in Birds: Genetic Factors Modulate Non-Genetic Maternal Influences. PLOS ONE 6, e14604. https://doi.org/10.1371/journal.pone.0014604

Houdelier, C., Pittet, F., Guibert, F., de Margerie, E., Lumineau, S., 2013. Non-genetic Inheritance in Birds: transmission of behaviour from mother to offspring. Non-Genetic Inheritance 1. https://doi.org/10.2478/ngi-2013-0007

Huver, R.M.E., Otten, R., de Vries, H., Engels, R.C.M.E., 2010. Personality and parenting style in parents of adolescents. Journal of Adolescence 33, 395-402. https://doi.org/10.1016/j.adolescence.2009.07.012

Kaiser, S., Sachser, N., 2005. The effects of prenatal social stress on behaviour: mechanisms and function. Neuroscience \& Biobehavioral Reviews 29, 283-294. https://doi.org/10.1016/j.neubiorev.2004.09.015

Kilner, R., 1995. When do canary parents respond to nestling signals of need? Proceedings of the Royal Society of London. Series B: Biological Sciences 260, 343-348. https://doi.org/10.1098/rspb.1995.0102

Kilner, R., Johnstone, R.A., 1997. Begging the question: are offspring solicitation behaviours signals of need? Trends in Ecology \& Evolution 12, 11-15. https://doi.org/10.1016/S0169-5347(96)10061-6

Kober, M., Trillmich, F., Naguib, M., 2008. Vocal mother-offspring communication in guinea pigs: females adjust maternal responsiveness to litter size. Front Zool 5, 13. https://doi.org/10.1186/1742-9994-5-13

Kölliker, M., Richner, H., 2001. Parent-offspring conflict and the genetics of offspring solicitation and parental response. Animal Behaviour 62, 395-407. https://doi.org/10.1006/anbe.2001.1792

Le Bot, O., Lumineau, S., de Margerie, E., Pittet, F., Trabalon, M., Houdelier, C., 2014. Long-life partners or sex friends? Impact of parental pair bond on offspring personality. Journal of Experimental Biology 217, 4184-4192. https://doi.org/10.1242/jeb.108738

Leboucher, G., Richard-Yris, M.A., Williams, J., Chadwick, A., 1990. Incubation and maternal behaviour in domestic hens: Influence of the presence of chicks on circulating luteinising hormone, prolactin and oestradiol and on behaviour. British Poultry Science 31, 851-862. https://doi.org/10.1080/00071669008417316

Liu, D., Diorio, J., Tannenbaum, B., Caldji, C., 1997. Maternal Care, Hippocampal Glucocorticoid Receptors, and Hypothalamic-Pituitary-Adrenal Responses to Stress. Science 277, 1659-1662. https://doi.org/10.1126/science.277.5332.1659

Maccari, S., Piazza, P.V., Kabbaj, M., Barbazanges, A., Simon, H., Moal, M.L., 1995. Adoption reverses the long-term impairment in glucocorticoid feedback induced by prenatal stress. J. Neurosci. 15, 110-116. https://doi.org/10.1523/JNEUROSCI.15-0100110.1995 
Madec, I, Gabarrou, J., Pageat, P., 2008. Influence of a maternal odorant on copying strategies in chicks facing isolation and novelty during a standardized test. Neuro Endocrinol Lett 29, 507-511.

Maestripieri, D., 2005. Early experience affects the intergenerational transmission of infant abuse in rhesus monkeys. PNAS 102, 9726-9729. https://doi.org/10.1073/pnas.0504122102

Maestripieri, D., 1993. Maternal Anxiety in Rhesus Macaques (Macaca mulatta). Ethology 95, 32-42. https://doi.org/10.1111/j.1439-0310.1993.tb00454.x

Mas, F., Kölliker, M., 2008. Maternal care and offspring begging in social insects: chemical signalling, hormonal regulation and evolution. Animal Behaviour 76, 1121-1131. https://doi.org/10.1016/j.anbehav.2008.06.011

Meek, L.R., Dittel, P.L., Sheehan, M.C., Chan, J.Y., Kjolhaug, S.R., 2001. Effects of stress during pregnancy on maternal behavior in mice. Physiology \& Behavior 72, 473-479. https://doi.org/10.1016/S0031-9384(00)00431-5

Mondloch, C.J., 1995. Chick hunger and begging affect parental allocation of feedings in pigeons. Animal Behaviour 49, 601-613. https://doi.org/10.1016/00033472(95)80193-6

Moore, C.L., Power, K.L., 1986. Prenatal stress affects mother-infant interaction in norway rats. Developmental Psychobiology 19, 235-245. https://doi.org/10.1002/dev.420190309

Murray, C.B., McPhail, J.D., 1988. Effect of incubation temperature on the development of five species of Pacific salmon (Oncorhynchus) embryos and alevins. Can. J. Zool. 66, 266-273. https://doi.org/10.1139/z88-038

Orcutt, F., Orcutt, A., 1976. Nesting and Parental Behavior in Domestic Common Quail. AUK 93, 135-141.

Paquet, M., Smiseth, P.T., 2017. Females manipulate behavior of caring males via prenatal maternal effects. PNAS 114, 6800-6805. https://doi.org/10.1073/pnas.1619759114

Pérez-Laso, C., Ortega, E., Martín, J.L.R., Pérez-Izquierdo, M.A., Gómez, F., Segovia, S., Del Cerro, M.C.R., 2013. Maternal care interacts with prenatal stress in altering sexual dimorphism in male rats. Hormones and Behavior 64, 624-633. https://doi.org/10.1016/j.yhbeh.2013.07.009

Pittet, F., Coignard, M., Houdelier, C., Richard-Yris, M.-A., Lumineau, S., 2012. Age Affects the Expression of Maternal Care and Subsequent Behavioural Development of Offspring in a Precocial Bird. PLoS ONE 7, e36835. https://doi.org/10.1371/journal.pone.0036835

Pittet, F., Houdelier, C., de Margerie, E., Le Bot, O., Richard-Yris, M.-A., Lumineau, S., 2014a. Maternal styles in a precocial bird. Animal Behaviour 87, 31-37. https://doi.org/10.1016/j.anbehav.2013.10.025

Pittet, F., Houdelier, C., Le Bot, O., Leterrier, C., Lumineau, S., 2014b. Fearfulness Affects Quail Maternal Care and Subsequent Offspring Development. PLoS ONE 9, e102800. https://doi.org/10.1371/journal.pone.0102800

Pittet, F., Houdelier, C., Lumineau, S., 2014c. Precocial bird mothers shape sex differences in the behavior of their chicks. Journal of Experimental Zoology Part A: Ecological Genetics and Physiology 321, 265-275. https://doi.org/10.1002/jez.1858

Pittet, F., Le Bot, O., Houdelier, C., Richard-Yris, M.-A., Lumineau, S., 2013. Motherless quail mothers display impaired maternal behavior and produce more fearful and less socially motivated offspring. Developmental Psychobiology n/a-n/a. https://doi.org/10.1002/dev.21129 
Pittet, F., Tyson, C., Herrington, J.A., Houdelier, C., Lumineau, S., 2019. Postnatal care generates phenotypic behavioural correlations in the Japanese quail. Behav Ecol Sociobiol 73, 120. https://doi.org/10.1007/s00265-019-2735-3

Power, K.L., Moore, C.L., 1986. Prenatal stress eliminates differential maternal attention to male offspring in Norway rats. Physiology \& Behavior 38, 667-671. https://doi.org/10.1016/0031-9384(86)90262-3

Preston, S.D., de Waal, F.B.M., 2002. Empathy: Its ultimate and proximate bases. Behavioral and Brain Sciences 25, 1-20. https://doi.org/10.1017/S0140525X02000018

Richard-Yris, M.A., 1994. Comportement parental chez les gallinacées : Importance du facteur émotivité dans la vitesse d'émergence des réponses parentales. Apport du modèle caille japonaise., in: Comportement et Bien-Être Animal. Picard M., Porter R.H., Signoret J.D., Paris, pp. 61-77.

Richard-Yris, M.A., Leboucher, G., 1987. Responses to successive test of induction of maternal behaviour in hens. Behavioural Processes 15, 17-26. https://doi.org/10.1016/0376-6357(87)90030-1

Richard-Yris, M.A., Michel, N., Bertin, A., 2005. Nongenomic inheritance of emotional reactivity in Japanese quail. Developmental psychobiology 46, 1-12.

Riedstra, B., Groothuis, T.G.G., 2004. Prenatal light exposure affects early feather-pecking behaviour in the domestic chick. Animal Behaviour 67, 1037-1042. https://doi.org/10.1016/j.anbehav.2003.10.009

Romanoff, A.L., 1936. Effects of Different Temperatures in the Incubator on the Prenatal and Postnatal Development of the Chick. Poultry Science 15, 311-315. https://doi.org/10.3382/ps.0150311

Roosenburg, W.M., Kelley, K.C., 1996. The Effect of Egg Size and Incubation Temperature on Growth in the Turtle, Malaclemys terrapin. Journal of Herpetology 30, 198-204. https://doi.org/10.2307/1565510

Schwabl, H., 1996. Maternal testosterone in the avian egg enhances postnatal growth. Comparative Biochemistry and Physiology Part A: Physiology 114, 271-276. https://doi.org/10.1016/0300-9629(96)00009-6

Smiseth, P.T., Scott, M.P., Andrews, C., 2011. Hormonal regulation of offspring begging and mediation of parent-offspring conflict. Animal Behaviour 81, 507-517. https://doi.org/10.1016/j.anbehav.2010.11.029

Stěhulová, I., Špinka, M., Šárová, R., Máchová, L., Kněz, R., Firla, P., 2013. Maternal behaviour in beef cows is individually consistent and sensitive to cow body condition, calf sex and weight. Applied Animal Behaviour Science 144, 89-97. https://doi.org/10.1016/j.applanim.2013.01.003

Wauters, A., Richard-Yris, M., Talec, N., 2002. Maternal Influences on Feeding and General Activity in Domestic Chicks. Ethology 108, 529-540. https://doi.org/10.1046/j.14390310.2002.00793.x

Weinstock, M., 2008. The long-term behavioural consequences of prenatal stress. Neuroscience \& Biobehavioral Reviews 32, 1073-1086. https://doi.org/10.1016/j.neubiorev.2008.03.002

White, A.M., Swaisgood, R.R., Czekala, N., 2007. Differential Investment in Sons and Daughters: Do White Rhinoceros Mothers Favor Sons? J Mammal 88, 632-638. https://doi.org/10.1644/06-MAMM-A-180R2.1 